\title{
TUR E IRAJ, CAÍN Y ABEL: SEMEJANZAS ICONOGRÁFICAS EN LA INTERMINABLE LUCHA DEL MAL Y EL BIEN
}

\author{
TUR AND IRAJ, CAIN AND ABEL: ICONOGRAPHICAL SIMILARITIES IN \\ THE INTERMINABLE STRUGGLE BETWEEN EVIL AND GOOD.
}

\section{Cristina Igual Castelló} Universitat Jaume I

\begin{abstract}
The duality between good and evil is a common topic in all civilizations regardless of chronology or geographical location. It is a conflict reflected in art history, and on the present occasion, through the iconographic types of Cain killing Abel as well as Tur murdering Iraj. The roots of these myths are deeply embedded in two highly relevant written sources, the Bible and the Shahnameh or The Book of Kings. The latter was written by the great Iranian poet Ferdowsi. The legends, despite having different origins, nevertheless have many similarities and they share a particular iconographic type. I analyze each of the myths along with their pictorial representations, which connect the thought of different cultures.
\end{abstract}

KEYWORDS: Tur, Iraj, Caín, Abel, Shahnaméh, Bible, envy, iconographic type.

RESUMEN: La dualidad entre el bien y el mal es un tema común en todas las civilizaciones independientemente de la cronología o la localización geográfica. Un conflicto reflejado en la historia del arte y en esta ocasión, figurado a través de los tipos iconográficos de Caín matando a Abel así como Tur asesinando a Iraj. Mitos que hunden su raíz en dos fuentes escritas de gran relevancia, la Biblia y el Shahnaméh o Libro de los Reyes, esta última redactada por el gran poeta iraní Ferdousí. Las leyendas, pese a tener un origen distinto, poseen numerosas similitudes y comparten un tipo iconográfico concreto. Analizamos cada uno de los mitos junto con sus representaciones pictóricas, conectando el pensamiento de las distintas culturas.

PALABRAS CLAVES: Tur, Iraj, Caín, Abel, Shahnaméh, Biblia, envidia, tipo iconográfico. 
El Arte ha forjado, a lo largo del tiempo, infinitas imágenes transmitiendo ideas, valores o narrando historias. A consecuencia de la labor del historiador del arte por analizar, catalogar y estudiar las diversas representaciones pictóricas como testimonio de la cultura, han surgido varios conceptos imprescindibles en la investigación iconológica. Para nuestra aportación es fundamental asumir las definiciones de tema y tipo iconográfico. La idea, el contenido o el concepto de la imagen son entendidos por tema, el cual adopta una representación determinada y se materializa visualmente en el tipo iconográfico (García Mahíques, 2009: 38-39). Algunos de los conjuntos visuales de índole narrativa han generado semejanzas en su modo de realización, dando lugar a un mismo tipo iconográfico compartido por dos temas dispares. Un ejemplo de este hecho se observa al estudiar las imágenes referentes al asesinato de Abel y al crimen de Tur, dos mitos engendrados en contextos diferentes, por culturas distantes, pero que encierran un mensaje común a la par que emplean un único lenguaje visual. En efecto, hacemos una comparativa entre ambos asuntos enfatizando en las similitudes conceptuales e iconográficas así como atendiendo a las diferencias derivadas de esta mirada reflexiva.

\section{EL SHAHNAMÉH Y LA BIBLIA: FUENTES DEL TEMA Y TIPO ICONOGRÁFICO}

El pasaje protagonizado por Tur e Iraj procede del Shahnaméh o Shah-Naméh, también conocido como El Libro de los Reyes, creado por el antiguo poeta Ferdousí. La magnífica obra literaria contempla la historia de Persia en cuatro dinastías, a través de las cuales se suceden cincuenta reinados previos al contacto islámico. A consecuencia de ello, el escrito distingue cuatro grandes periodos; el mitológico, el heroico y dos últimos de índole histórico. Independientemente del carácter de cada una de las partes, hay un rasgo común a todas ellas. La monarquía, al ser implantada por Dios, se presenta como una institución fuerte y duradera en el tiempo (Ahmad Reza Khezri, 2011: 153-154). Las raíces del poema profundizan hasta los $\mathrm{Jo}$ dainamehs, es decir, unas narraciones en prosa redactadas por cuatro escritores distintos entre los años 957-958 de la era cristiana, y confeccionadas expresamente para el rey Abumansur, monarca de Tus, donde se explicaba la historia de los antiguos reyes iraníes. El autor comenzó a escribir el poema en el año 990, una densa tarea en la cual invirtió entre 30 y 35 años aproximadamente. Redactado en la lengua natural, el farsí darí, se proclama como valioso testimonio sobre el pasado de Irán. Igualmente, es utilizado a modo de instrumento para el fomento de la identidad nacional, pues la pieza reúne un incalculable valor literario e histórico (Dadbín, 2007: 9-15). El poema recoge múltiples episodios épicos y nuestra atención recae en todos los hechos acaecidos en torno al personaje de Iraj, ya que texto del Libro de los Reyes es el arranque hacia la representación iconográfica de la leyenda.

Así como el Shahnaméh es la fuente literaria para el mito de Iraj, en la Biblia, y concretamente en el libro del Génesis, hallamos el escrito referencial por excelencia para la historia de Caín y Abel. Generalmente, por cercanía cultural, estamos más familiarizados con la narración bíblica que la iraní, aún así ambas garantizan ser de gran interés en su detallado estudio. Resulta necesario recordar que Caín y Abel eran los primeros hijos de Adán y Eva, el primero de ellos se dedicaba al cultivo de la tierra y el segundo a la crianza de ovejas. Llegado el día, uno y otro realizaron sus pertinentes oblaciones al Señor, Caín ofreció algunos de los frutos recogidos de la tierra y Abel sacrificó a los primogénitos de su rebaño. Dios, aceptando el 
gesto de Abel, alzó el humo de la hoguera, en cambio no aprobó el obsequio de Caín y en efecto, la humareda de su oblación no fue elevada. La evidente distinción, hacia ambos hermanos por parte de la divinidad, engendró en Caín un profundo sentimiento de envidia y deseo de venganza, por ello, en un acto desesperado, Abel fue asesinado a manos de su hermano (Gn, 4, 1-9). Como desvelaremos seguidamente al detenernos en la fábula de Iraj, el principal nexo de unión entre los relatos seleccionados es la existencia de un fratricidio, una acción concreta codificada iconográficamente y válida para la representación de cada crimen.

\section{EL REY FEREIDÚN Y SUS HIJOS SALM, TUR E IRAJ: GUERRA POR LA SOBERANÍA PERSA}

El Shahnaméh dedica dos dilatados y didácticos capítulos a la historia del monarca Fereidún y a la vida del príncipe Iraj ${ }^{1}$. El poema cuenta que el mundo era completamente gobernado por el mencionado soberano, quien después de unos años fue bendecido con la llegada de sus tres hijos. El primogénito, engendrado en el vientre Shahrnaz fue llamado Salm, un hombre poco valiente y necesitado de encontrar la seguridad y la estabilidad. De la misma madre nació posteriormente Tur, un joven extremadamente impulsivo. Y de Arnavaz, una segunda mujer, llegó el benjamín de los hermanos, Iraj, una simbiosis de dignidad y ferocidad, una persona inteligente y estimable a la cual sus actos le convertirían en un príncipe admirable. Tres muchachos con personalidades, valores y aspiraciones completamente dispares que protagonizarían una guerra ya vaticinada por su padre durante el estudio de los astros y los horóscopos. El monarca dividió el mundo en tres zonas y entregó cada una de ellas a uno de sus descendientes. Salm obtuvo las extensiones del Oeste, a Tur le otorgó China y el dominio de los turcos, e Iraj recibió Persia, la tierra de los guerreros. Además a este último, su padre le concedió la corona, la espada y el trono de marfil. Habiendo llegado el rey a ser anciano, la codicia se apoderó del alma de Salm y creció en él un pesado descontento y una sensación de injustica por la distribución de la tierra. Con ayuda de sus consejeros, diseñó un plan para reconsiderar la partición y envió un mensajero a la morada de su hermano Tur, el rey de China. El emisario transmitió el malestar y la indignación de Salm por la decisión de entregar Persia al príncipe Iraj. Tur, de acuerdo con su hermano, se reunió con él y juntos premeditaron cada una de sus actuaciones para saciar la sed de venganza. En primer lugar notificaron al rey Fereidún, mediante una amenazante epístola, su disconformidad: «Dios te entregó toda la tierra para gobernar, pero tú has actuado como un demonio loco. Tuviste tres hijos, todos valientes y bravos. Favoreciste a uno de ellos, le diste la corona de soberano, los otros dos fueron ignorados por ti. Nosotros no somos menos que él por el nacimiento, si él merece el estrado imperial, nosotros también. Y Dios nunca aprobará tu tratamiento preferencial por este hijo. Arranca la corona de su despreciable cabeza y dale algún rincón oscuro de la tierra para vivir. Si no lo haces, traeremos ejércitos de guerreros armados desde China, Turkestán y las tierras del Oeste para volver los días de Iraj en polvorientas noches y la humilde Persia con nuestro ejército. (op . cit., pp. 37-38)» Con otra carta por respuesta, el monarca manifiesta su deseo por el bienestar y la felicidad de sus tres hijos y anuncia

1. Relatamos la leyenda completa a partir de la nueva traducción de Dick Davis sobre la obra de FERDOUSÍ, Shahnaméh: The Persian Book of Kings. 
también el viaje tomado por Iraj hacia el encuentro de sus hermanos para alcanzar la reconciliación y la paz e implora que el pequeño sea tratado con respeto y amabilidad así como no sufra ningún daño.

Iraj fue recibido cordialmente y ello le hizo sentirse cómodo y relajado, alejado del peligro. Los soldados, que se hallaban a disposición de Salm y Tur, reconocieron en Iraj sus virtudes, lo consideraron merecedor del trono y lo alabaron como justo emperador. El primogénito, tras observar la traición de su ejército, empleó una larga noche reunido con Tur, tomando una decisión definitiva y estudiando el modo de llevarla a cabo hasta sus últimas consecuencias. Al despuntar el alba, se dirigieron hacia la tienda de Iraj donde tuvo lugar una tensa conversación, iniciada con los reproches de Tur: "Si tú eres más joven que nosotros, ¿por qué se te dio la corona más importante? Tú conseguiste Persia, es rica, y el trono y la corona de Kanayid, Persia no debe ser tuya. (op. cit., p. 42)» Iraj respondió con una humildad modélica: «Tú eres mi hermano mayor y ambicioso por la gloria; si tú quieres ser feliz debes calmarte. No quiero Persia, el Oeste o China, la soberanía o la autoridad sobre ningún país. No deseo pelear contigo y tu corazón no debe estar molesto con ninguna cosa que yo haga. No quiero gobernar este mundo. No deseo ninguna cosa excepto ser tu súbdito. (op. cit., p.43)» Las palabras de Iraj no quebraron la determinación de Tur y en un discurso desesperado apeló su clemencia: «¿No temes a Dios? ¿Es esta tu decisión? No me mates, porque mi sangre estará sobre tu cabeza. No hagas de ti mismo un asesino. No me volverás a ver. Yo estaré satisfecho con un rincón del mundo y poder ganar el pan en melancolía. ¿Cómo puedes derramar la sangre de tu hermano y atormentar el corazón de nuestro padre con un crimen? Querías el mundo, y ahora lo tienes. No derrames mi sangre, te vuelves en contra de Dios en este camino. (íbidem.)" Sin piedad y en un arrebato, Tur desenvainó una daga de su bota y clavó el arma envenenada en el torso de su hermano. Bañado en sangre, el cuerpo de Iraj se desplomó y expiró ${ }^{2}$. Inmediatamente después del asesinato, Tur envió una misiva al rey Fereidún escrita con una actitud de mofa para comunicarle la muerte del descendiente menor. Más tarde, Salm y Tur regresaron a sus respectivos reinos en el Oeste y China.

Los estudiosos entienden que la muerte de Iraj inaugura un nuevo periodo en la mitología persa, donde se desarrollará una densa guerra entre los reinos de Irán y Turán, a la vez que comienza el episodio heroico del Shahnaméh, con la soberanía del bisnieto de Iraj, el rey Manichichr (Curtis, 1996: 36). Efectivamente, el pasaje de Iraj sólo fue el estreno de las luchas fratricidas durante un largo tiempo, pues los descendientes de Tur siempre estuvieron enfrentados a los sucesores de Iraj. De hecho, los valores negativos se asociaron a los primeros, los turanios. En contraposición a estos, se encontraban los iranios, los portadores del bien (Ahmad Reza Khezri, 2011: 155).

Tras conocer la historia descrita en el Libro de los Reyes es oportuno tener en cuenta la mitología hebrea, donde uno de sus relatos plantea un novedoso origen a la disputa de Caín y Abel, el cual podemos relacionar con la leyenda iraní. Dicha tradición afirma que la tierra fue dividida entre los dos hermanos. A Caín se le otorgó el territorio y a Abel le pertenecían todos los animales. Tras pactar que ninguno de ellos se inmiscuiría en las pertenencias del otro, Caín cambió de parecer y quebró el acuerdo. Entonces, deseaba que todos los animales abandonaran su terreno, pero Abel se negaba a ello argumentando que no se dañaba el trabajo

2. Dick Davis en su traducción del Shahnaméh edita el momento crucial de la leyenda de la siguiente manera: «He drew a dagger from his boot and split Iraj from head to foot, so that his body was veiled in blood. He plunged the poisoned dagger into his brother's trunk. Iraj's body buckled, the noble cypress was felled, and the blossoms of his face ran with blood. This is how the young prince died. (op. cit., p. 43)» 
de Caín en la labranza. Aún así, el primogénito fue intolerante con su hermano y lo mató (Graves y Patai, 2000: 82). Aunque el relato referente a los hijos de Adán y Eva no tenga ninguna aceptación oficial y se trate de una leyenda paralela a la reconocida en las sagradas escrituras, llama la atención que, en ambas narraciones, la causa de la disputa sea el reparto de la tierra. Tiene su lógica que la tradición mitológica ubique la división de la tierra como origen del conflicto en uno y otro caso, pues pensemos que el territorio debió ser la primera fuente de riqueza y apropiación del ser humano.

\section{TUR MATANDO A IRAJ: EL TIPO ICONOGRÁFICO}

Los mitos han tenido un impacto y una difusión distinta en función de las circunstancias adyacentes a los mismos. El pasaje de Caín y Abel procede de una sagrada fuente escrita que, a la vez, resulta ser un pilar fundamental en el asentamiento del cristianismo. En efecto, sus representaciones son visibles en templos, lienzos de grandes artistas, volúmenes bíblicos y otros libros de culto miniados. En cambio, las escenas de Tur matando a Iraj sólo son perceptibles en los ejemplares ilustrados del Shahnaméh.

La combinación de la palabra y la imagen, tanto en las piezas cristianas como en el poema iraní, obedece principalmente a una función didáctica y moralizante. Se ofrecen unas enseñanzas donde subyace la continua disputa entre el bien y el mal. El ejemplar del Shahnaméh, datado en 1460, recoge en una de sus ilustraciones el momento del fratricidio [fig. 1]. La acción se halla emplazada frente a la tienda de Iraj, junto a un gran árbol que podemos relacionar con el antiguo pensamiento iraní según el cual, el bien y el mal eran ramas de un mismo árbol. En este sentido, los hermanos simbolizarían esas ramas que aún teniendo

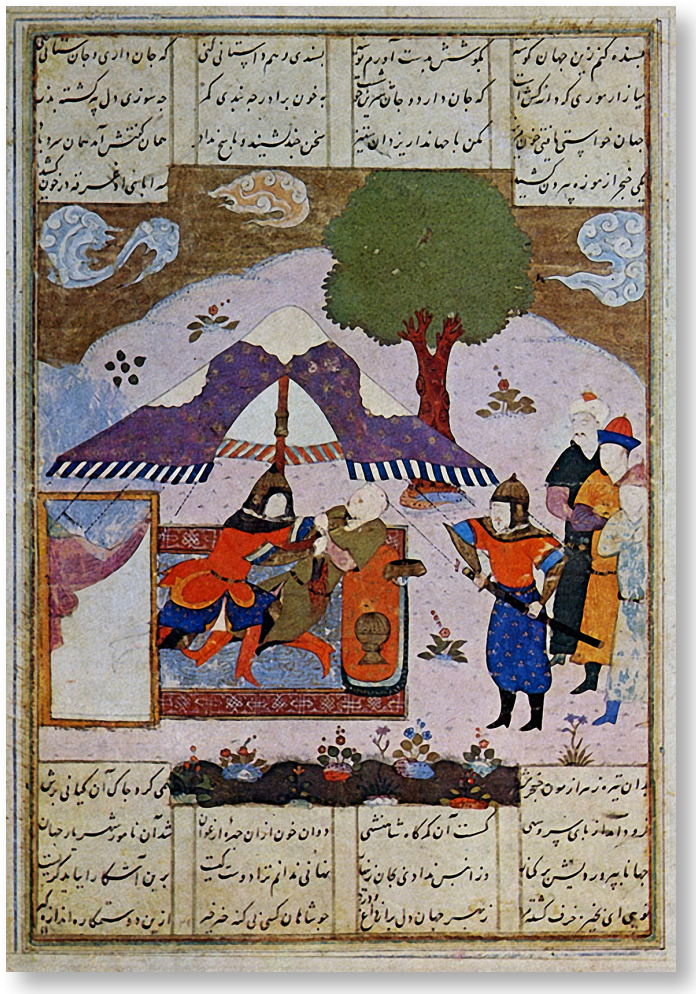

Fig. 1. Salm y Tur matan a Iraj, Shahnaméh, s. XV, Biblioteca Nacional de Rusia (San Petersburgo).

un origen en común pueden ser completamente opuestos. Y siguiendo la descripción de la leyenda, Tur se abalanza sobre su hermano hiriéndole mortalmente en el costado con la ayuda de una daga. A un lado Salm, con gesto de desenvainar su espada, es espectador del crimen. Especialmente, en esta composición iconográfica es palmario el cometido desempeñado por cada uno de los protagonistas según la personalidad que le ha sido asignada en la historia. Ferdousí califica a Salm de hombre poco valiente y por ello es quien diseña la tropelía e incentiva a Tur a consumar el ataque. Sin embargo, él se ubica en un segundo plano durante el asesinato, simplemente observa como su hermano, el decidido e impetuoso guerrero, sigue sus indicaciones y da muerte a Iraj. La víctima encarna, por tanto, lo valores positivos y los agresores tienen connotaciones 


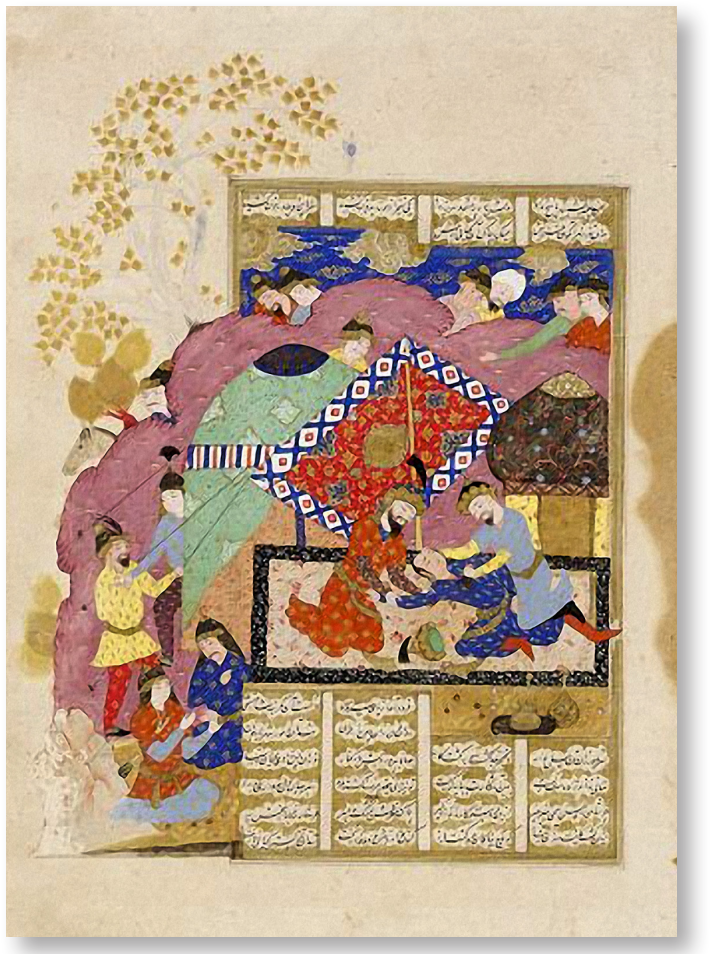

Fig. 2. Asesinato de Iraj por sus hermanos Tur y Salm, Shahnaméh, s. XVII, Museo de Arte Harvard.

negativas. Visualmente, la distinción se realiza mediante la indumentaria de los personajes. Las vestiduras de Salm y Tur son consonantes cromáticamente, una casaca roja combinada con un pantalón azul ornamentado con un bordado, y ambos quedan protegidos por un yelmo con yugulares y cubrenuca. El pequeño de los hermanos va ataviado con una especie de túnica verde, de modo más humilde y austero que sus consanguíneos, acorde con las virtudes que le eran adjudicadas. Parece ser que se desprende la corona desde su cabeza durante la embestida, la joya remite al momento de la donación por parte del rey hacia su hijo predilecto y causa del enfrentamiento. La imagen queda acompañada en la zona superior e inferior de la página por el texto poético y referente al suceso, y así alcanza su finalidad pedagógica.
Un conjunto pictórico más amplio y potencialmente narrativo obtenemos en este volumen del Shahnaméh del siglo XVII [fig. 2]. Al analizar la convivencia del texto y la imagen atisbamos una solución muy aguda por parte del artista. Un marco dorado encuadra la narración de la leyenda que es interrumpida, en el centro del espacio, por la representación del asesinato. No obstante, la imagen completa excede dicha limitación y nace junto al encuadre principal, presentando visualmente lo que parecen ser los hechos cronológicamente anteriores a la agresión. Los tres personajes son vestidos con las clásicas túnicas bordadas además de un cinturón sujetando la misma, unas botas por calzado y un gorro con plumín. El cambio cromático de cada uno de los atuendos contribuye a la diferenciación de los protagonistas. Así mismo la madurez de Salm y de Tur, frente a la juventud de Iraj, es remarcada mediante las facciones barbadas de los dos primeros en oposición al tercero, presentado como un hombre imberbe a la vez que inocente. Nuevamente, el menor de los hermanos es atacado con un puñal por Tur, mientras que Salm, en este caso no se encuentra al margen de la acción principal sino que retiene a la víctima por los brazos para facilitar el asesinato.

Del siglo XVI procede el ejemplar con la iluminación, objeto de nuestro interés, obrada por Muhammad Yusuf [fig. 3]. Para esta pieza el artista ha optado por modificar la composición iconográfica y quizá, en este caso, deberíamos reflexionar si dicha imagen verdaderamente pertenece al tipo iconográfico de Tur matando a Iraj o por el contrario, se debería catalogar en un tipo iconográfico diferente. Bajo nuestra perspectiva, y si somos fieles a las características y elementos necesarios en el diseño del tipo del asesinato, sería más apropiado ubicar en otro tipo iconográfico la imagen en cuestión, ya que son variadas las diferencias existentes entre esta y las restantes. Aún así, consideramos relevante analizar su iconografía e insertarla en el presente estudio. A día de hoy desconocemos 


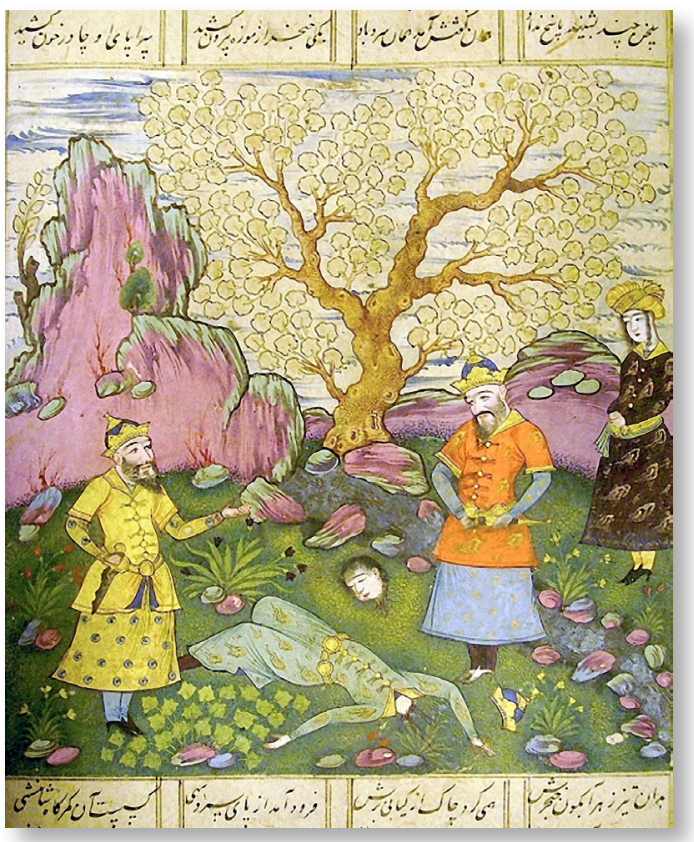

Fig. 3. Tur matando a Iraj, Shahnaméh, s. XVI, Biblioteca Británica (Londres).

la razón de estas distinciones pero es notorio observarlas con detalle. La principal de todas ellas, recae en el modo de cometer el acto criminal. El texto especifica el empleo de la daga para introducirla en el torso de Iraj, en cambio Yusuf ha preferido decapitar al personaje. Igualmente, no se representa la acción concreta de matar al muchacho, sino que se captura el momento posterior, cuando Salm y Tur mantienen un contacto visual y uno de ellos hace ademán de dirigirse al otro. Consecuentemente, podemos apreciar un nuevo tipo iconográfico de los momentos posteriores al fratricidio. El suceso tampoco está contextualizado en el campamento originario. Para esta ocasión, se ha elegido un entorno natural donde adquiere gran relevancia el árbol situado al fondo, con un amplio tronco que nace de la tierra y se separa en dos ramas principales, de las cuales surgen otras secundarias, refiriéndonos a que el bien y el mal comparten su origen aún siendo opuestos. Una vez más la diversidad en la indumentaria distingue a los personajes, generalmente

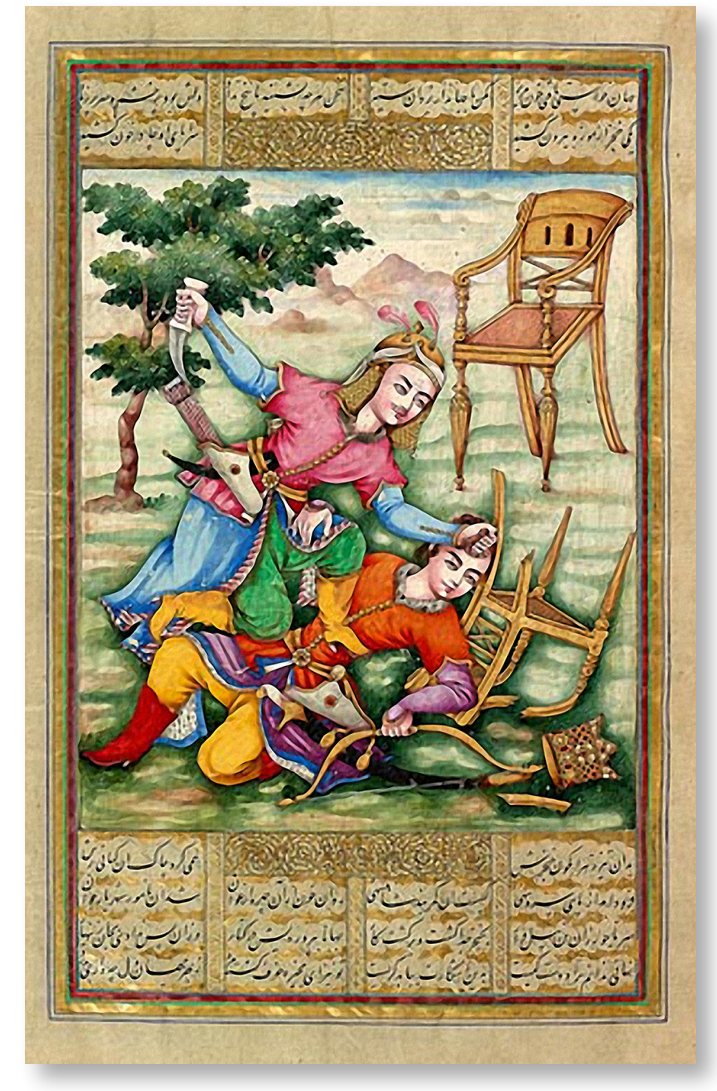

Fig. 4. Tur matando a Iraj, Shahnaméh, s. XIX, Biblioteca Morgan (Nueva York).

vestidos con una túnica larga o una casaca, faldón y medias de vistosos colores y ricamente bordadas. De nuevo, los rostros barbados de los dos hermanos mayores se oponen al imberbe de Iraj. No obstante, la igualdad categórica de los hijos de Fereidún se aprecia en las coronas, las tres son idénticas y aluden a la división de la tierra en tres reinos, adjudicados según la voluntad paterna y germen de la envidia que desencadenará la contienda. Siguiendo el estilo de las anteriores representaciones, el conjunto iconográfico se ubica en la zona central y está delimitado por las inscripciones poéticas tanto en la parte superior como en la inferior del folio.

Concluimos el breve repaso a las imágenes de Salm y Tur matando a Iraj con una excelente ilustración del siglo XIX [fig. 4]. 
En ella es preponderante el ataque de un hermano hacia el otro, el mayor empuña la daga a la vez que inmoviliza con su propio cuerpo a Iraj y se prepara para asesinarlo. La lujosa indumentaria sitúa a los reyes en su privilegiada categoría social, pues son los señores de China y Persia. El combate solo está complementado por varios elementos clave de la leyenda. Por un lado, aparece el árbol que alude a la dualidad del bien y del mal relacionable con los personajes. Y por otro lado observamos el trono de marfil roto y boca abajo, en contraposición a la intacta silla de gobierno de Tur, siendo una metáfora de la superioridad de un reino sobre otro. Además del trono, debemos destacar la espada y la corona caída de Iraj, dichos elementos fueron un especial regalo de Fereidún para enaltecer al pequeño de sus hijos.

\section{LA BIBLIA ILUSTRADA Y OTROS LIBROS: \\ LA ENSEÑANZA DEL PASAJE DE CAÍN Y ABEL}

De la multitud de imágenes que recogen el crimen de Caín hemos seleccionado algunas que iluminan la Biblia o forman parte de otras obras para el culto, pues la representación iconográfica se inserta en un libro, del mismo modo que el Shahnaméh, en muchos de sus episodios, se apoya de ilustraciones. La función de la imagen en un ejemplo y en otro, bajo unas circunstancias compartidas, es similar. Así pues su cometido didáctico queda reforzado al tener en cuenta que Caín y Abel no son personajes históricos, son los protagonistas de una fábula bíblica que tiene por objeto ofrecer una lección moral, determinar cuáles fueron las causas y consecuencias del primer asesinato, explicar la magnitud del pecado y el fundamento de la ira de Dios (Mertens, 1989 y Graves y Patai, 2000).
Las primeras representaciones de este pasaje insertadas en la Biblia se remontan a la Edad Media, cuando este manuscrito sagrado fue el ejemplar literario de mayor referencia. Se trataba de una lujosa obra al alcance de un estrecho círculo de privilegiados, pero aún así desempeñaban un importante cometido pedagógico ya que remarcaba visualmente el mensaje textual (Sebastián, 1988: 311). La Biblia Sacra confeccionada en el siglo XII, encontrada en la localidad de San Pedro de Cardeña y conservada en la Biblioteca Provincial de Burgos, dedica un amplio espacio a las ilustraciones del Génesis. Bajo la representación de Adán y Eva, aparece el conflicto de los primeros hijos de estos. En detalle, Caín introduce fieramente un puñal en el costado de Abel, generándole una herida de la cual brota abundante sangre. Ambos hermanos son representados físicamente de modo semejante, para poner énfasis en la igualdad entre los dos muchachos. Como hemos podido observar anteriormente, el poema iraní también recurre al fratricidio mediante un ataque de arma blanca.

Pero si en la Biblia burgalesa la representación pictórica impera íntegramente en el folio, disponemos de otros ejemplos donde la fusión entre la escritura y la imagen es plena. De hecho, podemos deleitarnos con una Biblia historiada escrita por Guyart des Moulins e iluminada por Jean le Noir en el siglo XIV [fig. 5]. El texto fue redactado en francés y dispuesto en dos columnas con las correspondientes letras capitales trabajadas en grisalla y coloreadas ligeramente en tonos rojos y azules. Por ello, en el libro del Génesis encontramos una miniatura que inmortaliza el instante posterior a la muerte de Abel. El muchacho aparece yacente con la herida mortal en la cabeza y su hermano, todavía armado, se enfrenta a la ira de Dios. La escena se concentra al abrigo de la letra $c$ en mayúscula, pues el texto comienza nombrando a Caín. El método de ornamentación para las iniciales aquí dispuesto llega 


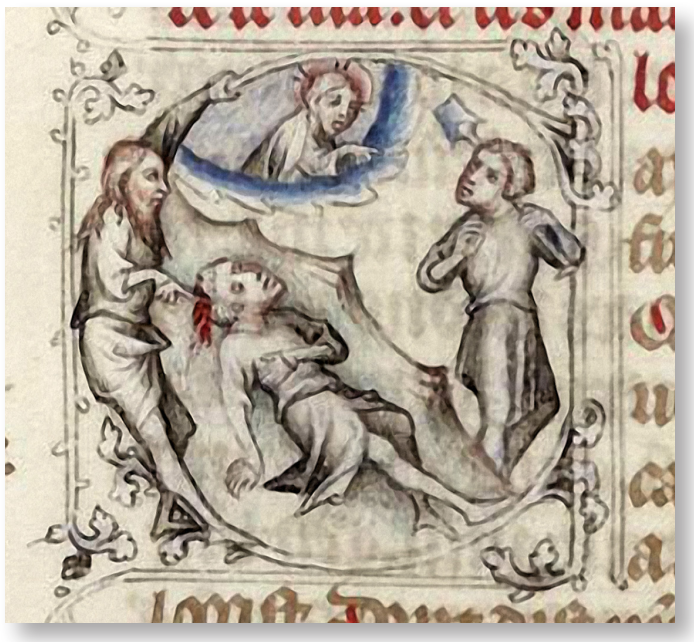

Fig. 5. Inicial historiada con el asesinato de Abel, Biblia historiada, Guyart des Moulins, s. XIV, Biblioteca de l'Arsenal.

tras un proceso de crecimiento en el arte de iluminar manuscritos, ya que de introducir unos escasos trazos figurativos, se progresó a capturar una imagen completa (Villaseñor, 2009: 39). Aunque, en este ejemplo, el tipo iconográfico no se corresponda con la acción concreta y necesaria para consumar el asesinato, hemos considerado oportuno incluirlo en el estudio por su interés al integrar con maestría una síntesis visual del escrito.
Sin embargo, otros volúmenes bíblicos sí que se hacen eco específicamente de la iconografía de Caín matando a Abel. Resulta muy interesante una Biblia moralizada, datada en torno a los años 1349 - 1352, e iluminada por Jean Pucelle, el Maestro de Remède de Fortune y Jean de Montmartre [fig. 6]. Por su cronología, el manuscrito pertenece a un periodo decadente en el arte de la iluminación, un momento posterior al máximo rendimiento en la ilustración marginal con la inclusión de nuevas técnicas y métodos de representación, cuando Pucelle gozaba de una gran reputación (Villaseñor, 2009: 41). En este caso, un escueto texto tanto en la lengua latina como en la francesa es acompañado por las imágenes explicativas del mismo. Así pues en el espacio superior del folio convergen las escenas, concretamente en el interior de dos decoraciones arquitectónicas que sirven de marco para las representaciones del pasaje. A la izquierda, Caín y Abel frente a un altar común hacen sus respectivas oblaciones. La figura de Dios, naciente desde el cielo, se dirige al menor de los jóvenes y lo bendice, mostrando así su predilección por Abel. En consecuencia, el primogénito se acerca por la espalda a su hermano y se dispone a ma-

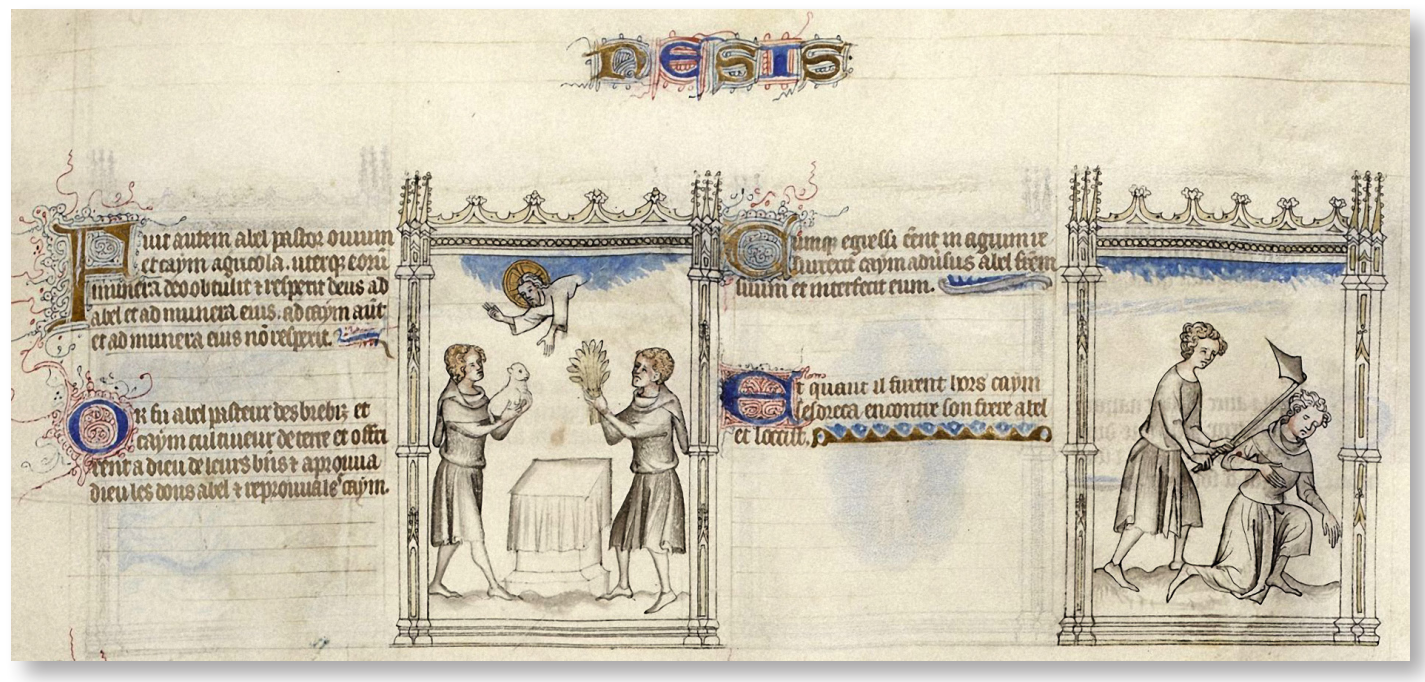

Fig. 6. Caín y Abel, Biblia moralizada, s. XIV, Biblioteca Nacional de Francia.

IMAGO, NÚM. 6, 2014, II7-128 


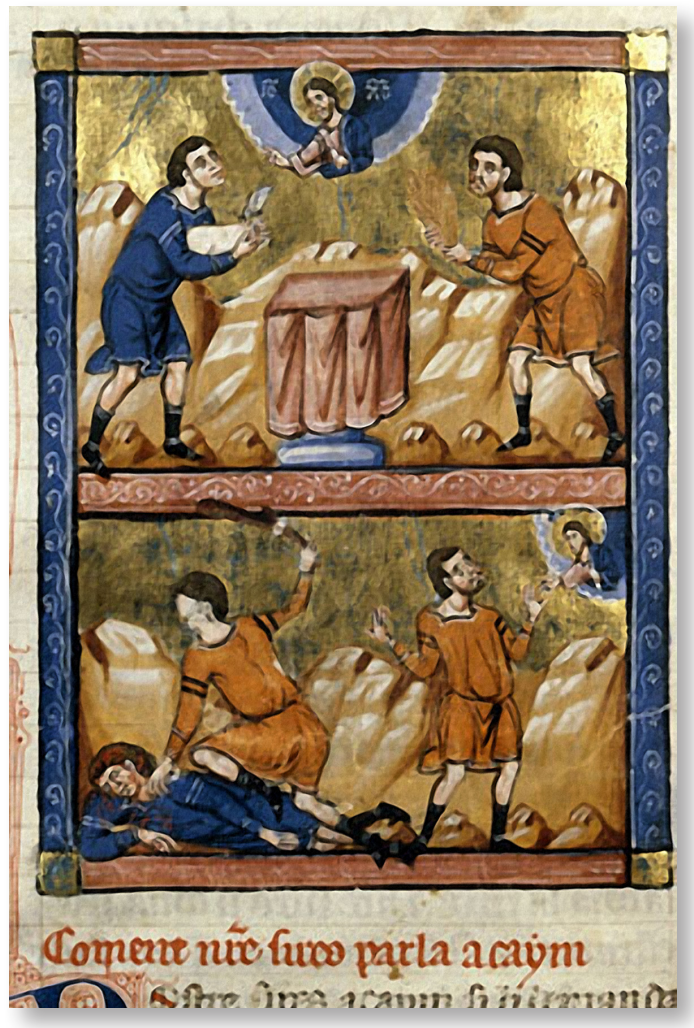

Fig. 7. Caín y Abel, Biblia, s. XIII, San Juan de Acre.

tarlo con la ayuda de un hacha. Esta imagen pertenece a los escasos ejemplares en los que la agresión se realiza por la espalda de la víctima, otorgando un aire de cobardía al criminal que no se atreve a dañar a su propio hermano de frente.

En la miniatura procedente de San Juan de Acre [fig. 7], generada en torno los años 1260 y 1270, los motivos iconográficos se concentran en un marco ornamental para estructurar la combinación de la literatura y la imagen. En esta ocasión, el texto está precedido por el conjunto pictórico que comprime los tres momentos cruciales de la leyenda, las oblaciones, el asesinato y el diálogo entre Caín y la divinidad tras el suceso. El altercado sigue las pautas establecidas en el tipo iconográfico correspondiente, el primogénito sostiene fuertemente una rama del árbol de la ciencia y alza el brazo para asestar el golpe mortal a su hermano. La identidad de cada uno de los personajes se asigna mediante la indumentaria, aunque similar para los dos hombres, quienes llevan una túnica de longitud media, se diferencian en su color rojo y azul, facilitando su identificación. En los ejemplares del Libro de los Reyes también hemos visto el sentido narrativo de las imágenes, donde la acción principal se encuentra acompañada por escenas precedentes para contextualizar el hecho trascendental.

Junto con las escrituras sagradas tenemos otros libros de índole cristiano que, en ocasiones, recogen la fábula del primer fratricidio. A modo de ejemplo la obra Speculum Humanae Salvationis, de comienzos del siglo XIV, continúa enfatizando en el sentido narrativo de la leyenda [fig. 8]. La imagen enmarcada, en convivencia con el escrito referente a la misma, presenta dos escenas del mito. En un segundo plano vemos el origen de la contienda, es decir, las hogueras en señal de ofrenda a la divinidad. Y en un primer término, apreciamos la incontrolable ira de Caín al agredir a su hermano. Abel tendido sobre la hierba de una colina espera indefenso el golpe mortal, su hermano empuña en esta ocasión una quijada de asno. Otros autores (Martinengo, 2004) han profundizado en la razón de la utilización de la mandíbula de un animal como arma homicida, y justifican esta introducción con la confusión histórica del pasaje de Caín y Abel con Sansón y los filisteos, pues este acabó con la vida de mil infieles ayudándose de una quijada (Jc 15,15-16). Largas y blancas túnicas, sugestivas de la moda oriental, visten a los personajes idénticamente, subrayando la igualdad entre los dos hermanos. Sólo un mínimo detalle, el portar o no el gorro, diferencia a Caín de Abel y ayuda al lector a distinguir a los protagonistas. 


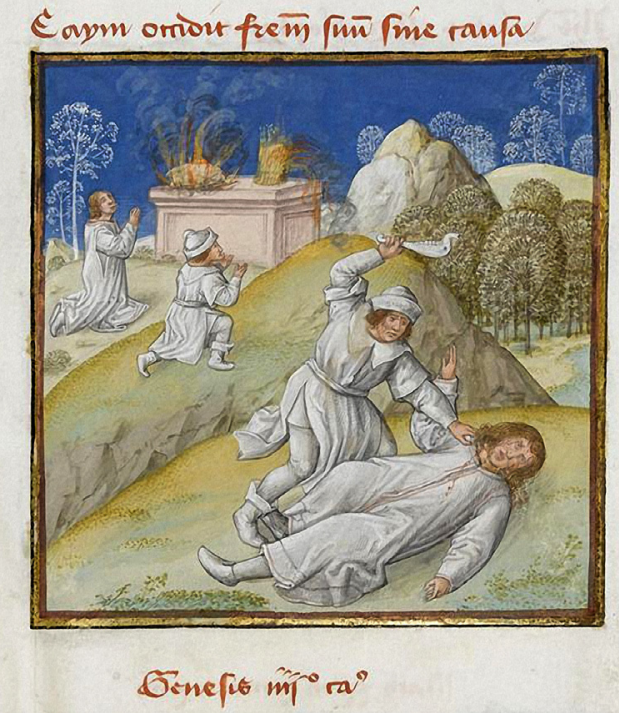

Fig. 8. Caín y Abel, Speculum Humanae Salvationis, s. XIV Museo Condal de Chantilly.

\section{CONFLICTO DEL BIEN Y EL MAL EN LAS DOS LEYENDAS: SIMILITUDES DE IRAJ Y ABEL EN CONTRAPOSICIÓN A TUR Y CAÍ́N.}

Los pasajes mitológicos analizados a través de las diversas imágenes manifiestan, en sus respectivas culturas, los contrarios pero inseparables conceptos del bien y el mal. Unas ideas materializadas en una pareja y un trío de hermanos entre los cuales se genera la disputa. El hecho de que sean consanguíneos enfatiza la creencia en que lo positivo y lo negativo siempre van a estar unidos. Dicha dualidad es inherente a la raza humana independientemente de las condiciones cronológicas, geográficas y culturales, por ello es un aspecto tratado en cualquier sociedad.
Además, las situaciones desencadenadas en los escritos cristianos y en el poema iraní comparten la esencia de su historia. Caín y Tur, este último junto con Salm, son mayores en edad que las víctimas, Abel e Iraj. La envidia es el sentimiento precursor de los asesinatos, Caín, Salm y Tur no celebran la prosperidad de sus hermanos y desean aquello que era del otro. Los celos son una reacción natural de los humanos ante las distinciones a las cuales nos vemos sometidos, somos vulnerables cuando nos consideramos diferentes e inferiores al resto del grupo. Vivir en sociedad nos conduce a buscar la aceptación del otro para sentirnos parte de un todo. No manejamos correctamente las circunstancias en las que un semejante es favorecido o es propicio hacia alguien. Dios el creador del mundo, escogió la ofrenda de Abel, lo desigualó de su hermano Caín, quien no aceptó la diferenciación, llegando a sentirse rechazado y furioso. También el monarca Fereidún, soberano de toda la tierra, distinguió a Iraj de sus otros hijos y le concedió al predilecto mayores privilegios, como la espada, la corona, el trono de marfil y el gobierno de un reino fructífero.

Generalmente el enfrentamiento es directo y primitivo, una lucha de cuerpo a cuerpo, donde el criminal va armado, se abalanza inesperadamente sobre la víctima y la sentencia de muerte. Puesto que Ferdousí especifica en la leyenda el tipo de arma utilizada, observamos que Iraj siempre es matado con una daga, concretamente un tipo de arma blanca de hoja corta y comúnmente apreciada en Persia. Por el contrario, la Biblia no perfila este detalle en su relato y la tradición iconográfica de Caín y Abel ha asumido variaciones respecto a esto, por ello tenemos representaciones donde el primogénito sostiene una piedra, una rama del árbol de la ciencia, una quijada de asno, un

3. De dicha consideración en la Patrología Latina hallamos como ejemplo la afirmación de Honorio de Autún, un popular teólogo cristiano del siglo XII que nos indica: "sicut sacrificum Abel, qui obtulit in figura Christi agnum.» Patrología Latina: the full text database, <http://pld.chadwyck.co.uk/> 17-08-14. 
hacha o un puñal. Sin embargo, un detalle digno de suscitar nuestra atención es la herida realizada durante el ataque, hay coincidencias entre la escena de Tur e Iraj con las imágenes de Caín matando con un puñal a Abel. Normalmente la lesión se sitúa en el costado izquierdo de la víctima, ello obtiene una especial relevancia en la cultura cristiana pues las fuentes patrísticas ${ }^{3}$ colocan a Abel como una prefiguración de Cristo, quien también fue agredido por una lanza cuando estaba en la cruz.

Ubicando en un segundo plano las diferenciaciones entre los personajes sobre las vestiduras, las armas empleadas y el contexto en el cual ha tenido lugar el crimen, las representaciones de ambos asesinatos coinciden en el lenguaje constructivo del tipo iconográfico. Por ello, en cualquier caso observamos una disputa entre dos hombres, el agresor y mayor de ellos apresa físicamente a la víctima, a la par que procede a herirla. Además del ataque, que es el componente referencial en el tipo iconográfico, suelen aparecer elementos secundarios evocadores del origen del conflicto. En el caso de Caín y Abel, es común apreciar los altares donde tuvieron lugar las oblaciones, momento en el que Dios les diferenció. Y en la fábula de Iraj visualizamos la corona, como objeto de la disputa, e incluso pueden aparecer la espada y el trono.

El Shahnaméh, las biblias y otros escritos miniados fusionan la imagen con el texto. No obstante, recibe más protagonismo el grupo iconográfico porque resume el pasaje en la acción clave de la leyenda y al mismo tiempo, atiende a la doble labor de la pieza, es decir, facilitar la extracción de una enseñanza además de ilustrar el texto.

El dilema entre el bien y el mal planteado en las dos narraciones mitológicas finaliza con el triunfo del antagonista, hay una superación en el plano terrenal de Caín y Tur, una victoria del mal, pero la identidad de las víctimas persiste en la posteridad. Abel e Iraj son recordados y ensalzados por sus virtudes, son objeto de múltiples elogios y testimonio de que el bien triunfa sobre la eternidad.

\section{BIBLIOGRAFÍA}

AHMAD REZA KHEZRI, S. [2011]. Persia: cuna de civilización y arte: historia, literatura, arte, religión, Córdoba, Almuzara.

CURTIS, V. S. [1996]. Mitos persas, Torrejón de Ardoz, Akal.

FERDOUSÍ, A. Shahnaméh: The Persian Book of Kings. Traducción de Dick Davis [2006].

FERDOUSÍ, A. Shah-Naméh. El Libro de los Reyes: Historia de Siawash. Madrid, Hiperión. Traducción de Homá Dadbín [2007].

GARCÍA MAHÍQUES, R. [2009]. Iconografía e iconología. Cuestiones de método, Madrid, Encuentro.

GRAVES, R. y PATAI, R. [2000]. Los mitos hebreos, Madrid, Alianza.

MARTINENGO, A. [2004] «El Caín de Quevedo entre exégesis e iconografía», La Perinola, 8, 258-272.

MERTENS, HEINRICH A. [1989]. Manual de la Biblia: aspectos literarios, históricos, arqueológicos, históricos-religiosos, culturales y geográficos del Antiguo y Nuevo Testamento, Barcelona, Herder.

SEBASTIÁN LÓPEZ, S. [1988]. Iconografía medieval, Donostia, Etor.

VILLASEÑOR SEBASTIÁN, F. [2009]. Iconografía marginal en Castilla. 1454-1492. Madrid, CSIC. 